\title{
Hypothetical Estimate of Drug-Burden on a Diabetic Foot Ulcer Patient and its Relevance to Microbiological Analysis
}

\author{
C. Meenakshisundaram ${ }^{1 *}$, J. Uma Rani ${ }^{2}$, Usha Anand Rao ${ }^{2}$, V. Mohan ${ }^{3}$ and R. Vasudevan ${ }^{3}$ \\ ${ }^{1}$ Department of Microbiology, Sri Venkateswara Medical College and Research Centre, \\ Pondicherry-605 102, India \\ ${ }^{2}$ Department of Microbiology, Dr. A.L.M. Post-Graduate Institute of Basic Medical Sciences, \\ Tharamani Campus, University of Madras, Chennai-600 013, India \\ ${ }^{3}$ Dr.Mohan's Diabetic Specialties Research Centre, Gopalapuram, Chennai-600 028, India \\ *Corresponding author
}

A B S T R A C T

\begin{tabular}{l} 
Ke y w or d s \\
$\begin{array}{l}\text { Drug burden, } \\
\text { Diabetic foot ulcer } \\
\text { patients } \\
\text { Optimization of } \\
\text { antimicrobial } \\
\text { agents. }\end{array}$ \\
\hline Article Info \\
\hline $\begin{array}{l}\text { Accepted: } \\
\text { 17 May } 2017 \\
\text { Available Online: } \\
\text { 10 June } 2017\end{array}$ \\
\hline
\end{tabular}

\section{Introduction}

There is an increasing reason for optimism in offering treatment to diabetic foot ulcers, and other chronic wounds through enhanced understanding of pathogenic factors, at the advent of the latest improvements in identifying the causative agents versus suitable antibiotic agents (Cavanagh et al.,
2005; Lipsky et al., in "2012- IDSAGuidelines”). The Infectious Diseases Society of America (IDSA) classified diabetic foot infections into four classes, namely, i) Uninfected, ii) Mild, iii) Moderate to Severe, and iv) Severe, correlating with the corresponding clinical symptoms. Obviously, 
the treatment approaches could be different in each class.

The diagnosis must be correctly carried out, in order to proceed with the treatment option.

Weng et al., (2017) expressed a fear that any wrong diagnosis of a lower-extremity infection could lead to unnecessary medication and hospitalization charges, citing the estimated number of 50,000 to 130,000 misdiagnosed cases of Cellulitis, during the period of study, involving a wasteful expenditure of US\$ 195 million to 515 million, in the United States alone. This would vouch for the importance of the correct diagnosis, for which the clinical symptoms and microbiological test results are the guiding factors.

Gadepalli et al., (2006) suggested that amputation can be prevented, if the diabetic foot ulcer can be treated with adequate and timely care. This optimism gives a lot of hope for all the stake-holders, pointing towards a devoted-care needed in the task. However, the antibiotic resistance exerted by microbial pathogens against many antimicrobial agents administered on diabetic foot ulcer patients continues to pose a problem, often proving as a challenge to the therapeutic options preferred by clinicians.

Kruse and Edelman (2006) reported that the treatment to diabetic foot ulcer must address all three major concerns, namely, prompt debridement, offloading procedures, and infection control, and that antibiotic treatment must be started after initial culture tests, and that the treatment must be suitably modified, as revealed by subsequent culture tests. This sequence is important for initiating and enabling a quick-healing process.

Stevens et al., (2005) reported that the response to initial antibiotic therapy must be judged by the outcome, namely, reduction in fever and toxicity, and reduction in the advancement of infection. Ho Kwong Li et al., (2015) reported that oral therapy could not be considered as inferior to intravenous treatment, in terms of clinical outcomes, and that the cost of intravenous treatment system would involve ten times higher cost.

Lipsky et al., (2008) compared the effectiveness of Pexiganan (a topical cream) versus Ofloxacin (Oral), in the case of mildlyinfected Diabetic Foot Ulcer (DFU). Lauf et al., (2014) reported the efficacy and effectiveness of Tigecycline versus Ertapenem, in patients, with and without Osteomyelitis.

In any hospital setting, in India, the polymicrobial infection could be expected in the range of around $30.0 \%$ of the diabetic foot infection patients (Sajila et al., 2015).

It was reported that as many as 7-strains of different bacterial species were present in a polymicrobial infection in a single diabetic foot ulcer patient, in India, namely, Staphylococcus aureus, Enterococcus spp, Pseudomonas aeruginosa, Pseudomonas stuzeri, Escherichia coli, Proteus spp, and Alcaligenes spp. (Shahi et al., 2013).

The polymicrobial infections would often prove to be severe infections, or limbthreatening infections, requiring to be covered, in the antibiotic treatment, in the case of Gram-negative pathogens, as well as Gram-positive pathogens, among the aerobes and anaerobes (Grayson et al., 1995; Lipsky and Berendt et al., 2004; Rao and Lipsky et al., 2007; Reiber and Lipsky et al., 1998).

In the United States, Lipsky et al., (2005) compared the effectiveness of two antimicrobial agents prevalent in diabetic foot infections, in a major multi centre trial studies, in two separate groups, namely, 
administering Ertapenem @ 1.0 g daily, on the first-group of 295 diabetic foot infection patients, for 5-days, and giving Piperacillin/ tazobactam@3.375 g every 6-hours, on the second-group of 291 diabetic foot infection patients, for 5-days, and thereafter, giving Amoxicillin/clavulanic acid @ 825/125 mg every 12-hours, to both groups of patients. Investigators were given the freedom to decide on administering Vancomycin to patients of either group, for the purpose of giving coverage against the antimicrobial resistant Enterococcus species, and against the Methicillin resistant Staphylococcus aureus (MRSA). Based on clinical and microbiological outcomes, it was concluded that the effect of administering Ertapenem was equivalent to Piperacillin/tazobactam, and that the nature of adverse effects caused were similar, in both groups.

In China, Xu et al., (2016) compared the antibiotic regimens against the pathogens prevalent in diabetic foot infection of 443 patients, by administering Ertapenem on one group of 219 patients, and administering Piperacillin/tazobactam on another group of 224 patients. It was concluded that the treatment by Ertapenem was non-inferior to the treatment by Piperacillin/tazobactam, in respect of clinical outcome, microbiological outcome, and adverse effects experienced by the Chinese patients. It was also hinted that Ertapenem had a lower rate of clinical resolution in severe diabetic foot infections.

A report by Clinical trials, gov (2010), compared Tigecycline versus Ertapenem to check their effectiveness in offering treatment to diabetic foot infections. Such comparisons of two antimicrobial agents (AMAs) took into consideration the various factors, like, the number of patients getting cured out of the total number of patients treated, the number of patients affected with adverse effects such as blood and lymphatic system disorders, cardiac disorders, liver-damage, general disorders such as abdominal pain, renal or urinary disorders, mental status changes, chest pain, fever, septic shock, allergic reactions, metabolism and nutritional disorders, etc. These factors are related to the choice of antimicrobial agents, for each pathogen prevalent in the diabetic foot infection. Decision to select a particular antimicrobial agent could be based on rating of Noninferiority or Equivalence margin, such as $5.0 \%$ to $10.0 \%$.

In the Indian scenario, fungal pathogens were reported to be prevalent in chronic wounds of diabetic patients, in addition to bacterial pathogens (aerobic and anaerobic), in many locations in India (Bansal et al., 2008; Sanniyasi et al., 2015, Chincholikar et al., 2002). Anaerobic pathogens have been isolated and treated successfully by Anandi et al., (2004), with a multi-disciplinary involvement, in a teaching hospital setting.

In addition to the antimicrobial agents used for fighting against the infection, in a diabetic patient, certain oral-hypoglycemic drugs, also, need to be administered, for maintaining the desired glycemic control. According to Armstrong and Lipsky (2004), a diabetic foot ulcer patient must first be medically stabilized, and secondly, metabolic aberrations, if any, must be carefully addressed. This factor does have relevance to the "drug-burden" on the diabetic foot ulcer patient, in the case of patients already experiencing system-factors such as hypertension, hyperlipidemia, atherosclerotic heart disease, obesity or renal insufficiency, etc. This aspect, therefore, deserves to be given a due consideration, at the time of planning the type of treatment to be given to a diabetic foot ulcer patient, on a case to case basis (Rowe and Khardori, 2017).

In the case of poly-microbial infections, care must be taken to optimize the number of antibiotic classes, so that the adverse reactions 
which are characteristically unique to each class of antimicrobial agents cannot become additive, in their effects on the same patient. This effort of optimization of antibiotic classes would help avoiding the occurrence of undesirable adverse effect on the diabetic foot ulcer patient, thereby, reducing the "drugburden" on the patient.

In the selection of antimicrobial agents, the susceptibility patterns have to be considered, along with the probable adverse reactions/allergies/hyper sensitivity reactions, etc., which they could cause on the diabetic foot ulcer patient. Certain details need to be considered as listed below:

Allergy to Penicillin could vary from $5 \%$ to $10 \%$ of hospitalized patients (Green et al., 1971; Parker, 1972).

Borish et al., (1987) highlighted on the necessity to look for allergy to penicillin in patients, before deciding about the medication.

Bronze et al., (2017) reported that Amoxicillin/clavulanate is preferred as an alternative to patients who are feeling allergic, or intolerant to Macrolide class of antibiotics (Erythromycin, Azithromycin, and Clarithomycin) proving effective against Gram-positive cocci and some intracellular pathogens.

Bronze et al., (2017) also claimed that Ertapenem (Invanz) was stable against hydrolysis by a variety of beta-lactamases, including Penicillinases, Cephalosporinases, and Extended beta-lactamases (ESBLs).

Edmonds (2009) reported that Amoxicillin/clavulanate would be able to kill the bacteria which would prove resistant to Amoxicillin (if applied alone), and that the probability for the occurrence of hepatotoxicity in the patient would be around six- times greater with this Amoxicillin/clavulanate treatment.

Joseph and Axler (1990) reported that combination therapy containing Clindamycin and Aztreonam or Ciprofloxacin could be found helpful for diabetic foot infection patients who are allergic to Beta-lactam antibiotics, and that less-severe infections can be treated with a single antimicrobial agent such as Ticarcillin/clavulanic acid, or Ampicillin/sulbactam. Cephalosporins with anaerobic activity (Cefoxitin, or Cefotaxime, or Ceftizoxime) can be used, in areas where Enterococcus is not a major problem.

Thus, it becomes necessary to select the therapy based on the personalized metabolicsystem details of the patient, and also on the area-specific considerations. This is one reason as to why bacterial antibiotic sensitivity has to be assessed in each local centre, by testing appropriate AMAs against the pathogenic species.

\section{Indian scenario}

National Treatment Guidelines for Antimicrobial Use (2016) have been prescribed by the National Centre for Disease Control (NCDC) of the Ministry of Health and Family Welfare, Government of India, New Delhi, according to which the following hints are indicated, relevant to the selection of antimicrobial agents for treatment against Skin and Soft Tissue Infections:

For Vancomycin-resistant Enterococcal (VRE)-species, Linezolid has been indicated to be efficient, although it cannot be used for a long period of time, as intolerance may develop in some patients. Its use is not recommended for patients with impaired renal function. Daptomycin NOT approved for treatment of VRE-infection. Its use, as a Monotherapy, is not recommended. 
For the ESBL (Extended Beta-lactamase)producing Enterobacteriaceae, the Carbapenems (Imipenem, Meropenem, or Ertapenem) have been indicated as the drug of choice, for serious infections. For mild cases, Piperacillin/tazobactam or Cefoperazone/ sulbactam could be considered, when susceptibility in-vitro is favourably indicated.

Citing the CLSI-recommendations, it has been stated that ESBL-producing isolates must be considered resistant to all Penicillins, Cephalosporins (including Cefepime and Cefpirome) and Aztreonam, irrespective of the in-vitro test results. (It must be remembered that the emergence of ESBLproducing Enterobacteriaceae is related to indiscriminate use of Third Generation Cephalosporins).

For Carbapenem-resistant Enterobacteriaceae (CRE)-infections, involving ESBL, or AmpC and Porin-loss, or Acquired Carbapenemases, it has been indicated that either Polymixin, or Colistin, or Tigecycline and Fosfomycin can be recommended.

In the case of infections involving bones and joints, treatment must be based on culture of blood/synovial fluid/bone biopsy, and necessarily, with orthopaedic consultation.

(These guidelines provide the most authoritative information applicable to skin \& soft tissue infections. However, there is a need to generate more data at local and regional levels, in order to streamline efforts in the direction of augmenting endeavours to fight against the ever-increasing menace of antibiotic resistance. Such data can be made available to the National Data Bank on Bacterial antibiotic resistances, in the case of all diseases, in order to serve the purpose of justifying policy-formulations, related to therapeutic strategy enhancement (Meenakshisundaram et al., 2016).

\section{Factors related to glycaemic control}

Bansal et al., (2008) reported that about 67\% of the diabetic foot ulcer patients had random blood sugar (RBS)-levels greater than 200 $\mathrm{mg} / \mathrm{dL}$, and a majority of them had HbA1clevels above $7.0 \%$, and that, among the total of 103-diabetic foot ulcer patients, the HbA1c (\%) varied around 8.15+/-1.75.

In case of Hypoglycemia (blood sugar level dropping below $70 \mathrm{mg} / \mathrm{dL}$ ), treatment is given in the form of 15 to 20 gram of fast-acting carbohydrates, like a fruit juice, glucosetablet, sugar-cube, etc. But, fats or proteins, if consumed, can slow down the body's absorption of sugar, and may cause an increase in the blood sugar level (Mayo Clinic Diseases and Conditions: diabetic hypoglycemia, 2015).

In maintaining the glycemic control, Fernando et al., (2016) reported that glycemic interventions include subcutaneous insulin administration, continuous insulin infusion, oral-hypoglycemic drugs (anti-diabetes agents), life-style intervention or a combination of these interventions. Oral antidiabetes therapy include four classes of hypoglycemic drugs, namely, Sulfonylureas, Metformin, Thiazolidinedione's and Alphaglucosidase inhibitors. The main side-effects caused by alpha-glucosidase inhibitors are flatulence (intestinal gas-related problem) and diarrhea which are usually mild, and not necessitating the cessation of therapy. (Thomas Higgins, 2017).

Sawin et al., (2010) reported that Metformin did not cause hypoglycemia in hospitalized diabetic patients, and yet the theoretical risk of Metformin inducing lactic acidosis must be monitored.

The risk factors relating to the occurrence of increased lactic acidosis or increased lactate levels, in case of anti-diabetes drugs, such as Metformin versus other anti-hypoglycemic 
treatments, became a debate, and hence, the situation must be monitored (Salpter et al., 2006). Kendall et al., (2006) reported that persons with diabetes might avoid taking the antimicrobial agent Gatifloxacin, a thirdgeneration broad spectrum Fluoroquinolone which has activity against Gram-negative / Gram-positive (aerobic/anaerobic) and atypical pathogens, as it undergoes minimal bio-transformation, and is excreted renally Uckay et al., (2009), and Richard et al., (2008) reported that skin commensals, such as Coagulase negative Staphylococcus (CONS) spp, Corynebacterium spp, or Bacillus spp, would require treatment, only when associated with an infection involving osteosynthetic material or hardware.

\section{Factors related to cross-resistivity}

With regard to cross-resistivity between two antimicrobial agents or alternatives in the selection of antibiotics, the following points need to be considered:

Cephalosporins become acceptable to a majority of patients who were found to be allergic to Penicillin (Romano et al., 2004). However, in some cases, fatal ends have been reported (Pumphrey et al., 1999). Crossresistivity between Penicillins and Carbapenems were reported to be low (Romano et al., 2007).

There was no Cross-resistivity between Penicillins and Monobactam.

In the case of Quinolones, increases of IgEmediated anaphylactic reactions were reported, perhaps, due to the large scale use of the Quinolones (Manfredi et al., 2004; Hein, 1997; Sachs et al., 2006; Venturini Diaz et al., 2007). Aminoglycosides rarely cause hyper-sensitivity reactions, although some reports indicated the occurrence of $\mathrm{IgE}$ mediated systemic reactions (Solensky et al., 2010).
Chloramphenicol (on prolonged use, perhaps) was associated with anemia (resulting from decreased production or increased reduction of red blood cells), according to Smith Marsch (of the University of Illinois at Chicago) 2017).

\section{Side effects due to common antimicobial agents in use}

Anderson (2017) reviewed and updated an exhaustive list of antimicrobial agents, considering the various side-effects produced by each class of antibiotics, although it was concluded that the antimicrobial agents are generally safe, when used in "appropriate" doses. The highlights of side-effects are given below:

Penicillins (Ampicillin, Amc, Pi, Pi/t, Nafcillin, Oxacillin) causing hypersensitivity, including Anaphylaxis; (in addition to nausea, vomiting, diarrhea, skinrash, drug-fever, abdominal pain);

Cabapenems (Imipenem/cilastatin identified with probable hypersensitivity; Meropenem causing hypersensitivity in penicillin-allergy patients); in addition to diarrhea, nausea, vomiting, liver-toxicity, eosinophilic leukocytosis, Aminoglycosides (G, Tob, Ak), causing oto-toxicity or renal toxicity on longterm use; in addition to dizziness, nausea, vomiting, nystagmus (rhythmical oscillation of the eye-balls, either horizontal, rotary or vertical).

Cephalosporins (Cefolexin, Cefaclor, Cefuroxime, Ceftibuten, Cefdirnir, Cefixime, Ceftriaxone) causing cross-hyper sensitivity in penicillin-allergic patients; in addition to skin-rash, diarrhea, nausea, vomiting (although rare); serum-sickness (involving reaction by the immune system)

Glycopeptides (Vancomycin causing Red man syndrome; Televancin causing Taste- 
alteration), nausea/vomiting, headache, dizziness); Macrolides (Erythromycin, Azithromycin, Clarithromycin) causing sometimes high rate of intestinal side effects; in addition to diarrhea, nausea, vomiting, taste-alteration, anorexia (aversion for food)

Sulfonamides (T/S, Erythromycin/ sulfisoxazole, Sulfasalazine, etc) causing Stevens Johnson syndrome, Toxic epidermonecrolysis involving necrosis and loosening of tissues), photosensitivity; in addition to anorexia, dizziness, diarrhea, nausea, vomiting, headache, rash, abdominal pain

Tetracyclines (Tet, Doxi, Mino) causing Liver toxicity, Photosensitivity; in addition to diarrhea, nausea, vomiting, abdominal pain, anorexia (diminished appetite)

Quinolones (Cip, Lev, Mxf, Ofl) causing severe photosensitivity, Insomnia, abdominal pain, lethargy; in addition to diarrhea, nausea, vomiting

Metronidazole will cause metallic taste, in addition to nausea/vomiting, dizziness, headache; (Alcohol consumption while being treated with Metronidazole would aggravate symptoms). Lipsky et al., (2012b), also, described the relative merits and de-merits of many antimicrobial agents, to be used in oral route versus parenteral route.

The above sets of informations derived from literature, are to be treated as reference material (or hints) only. It must be inferred that the local data on bacterial sensitivity pattern, in the antimicrobial treatment, does play a major role in deciding the prospects of healing of the diabetic foot ulcer wound.

\section{Aim and objectives}

The present study was conducted with the following aim and objective:
To estimate the probable drug-burden which would result on the diabetic foot ulcer patient, in the treatment process, using the data on the bacterial pathogens isolated from the wound, and the data on antibiotic sensitivity, and

To assess whether any other antimicrobial agents are to be newly tested in India for their in-vitro susceptibility against each pathogen found in diabetic foot ulcers, based on hints acquired from international literature.

\section{Materials and Methods}

Pus swabs were collected from 75-diabetic foot ulcer patients being treated in Dr.V.Mohan's Diabetes Specialties Center, Gopalapuram, Chennai-600 028 (South India), during a period of 5-months, from May to September, 2005. The 104-pus samples collected from the patients were transported to the Laboratory in Carey-Blair transport medium of Hi-media (India). All the isolates were identified, adopting the standard procedures indicated in the NCCLS, 2002 (Meenakshisundaram et al., 2015). Drug resistance pattern of Pseudomonas aeruginosa only was evaluated using antimicrobial agents representing various classes of standard antimicrobial agents, namely, Ampicillin (10ug), Amoxicillin/clavulanic acid (20ug + 10ug), Piperacillin (100ug), Imipenem(10ug), Cefotaxime (30ug), Ceftazidime (30ug), Ceftriaxone (30ug), Gentamicin(10ug) and Ciprofloxacin (5ug).

Antimicrobial agents (AMAs), with a susceptibility range of $100.0 \%$ to $66.7 \%$ (facing bacterial resistance of $0.0 \%$ to $33.3 \%$ from Pseudomonas aeruginosa) were evaluated.

Bacterial resistance of other 8-bacterial species isolated in the diabetic foot ulcer specimens were not evaluated in the bacterial sensitivity test, in the retrospective study, due 
to limited scope of the study. In order to fill up this gap, antimicrobial susceptibility patterns reported in the literature in India, relating to diabetic foot infections, were used, choosing 2-other locations in South India, namely, Kelambakkam (near Chennai, Tamilnadu State, as reported by Priyadarshini et al., 2013), and Bengaluru (in Karnataka State, as reported by Sajila et al., 2015), and choosing 2-locations in North India, namely, Chandigarh (in Hariyana State, as reported by Bansal et al., 2008), and New Delhi (as reported by Gadepalli et al., 2006).

In all cases, antimicrobial agents (AMAs) effective against the pathogens in the susceptibility range of $100.0 \%$ to $66.7 \%$, as evaluated in the 5-cities in India, were compared with the data relating to similar data collected in the multicenter trial studies on diabetic foot ulcers, in the United States, as reported by Citron et al., (2007).

The overall drug-burden on the individual diabetic patient will correspond to the antibiotic agents needed to be administered on the patient, in order to eradicate all pathogens, inclusive of aerobic organisms, anaerobic organisms and fungal species prevalent in the patient. The drugs have to be optimally selected, so as to earn a healing of the wound, with minimum number of drug-types, so that the side-effects can be minimized. Allergies and cross-resistances become additional factors for consideration, in the selection of the drugs.

\section{Results and Discussion}

The prevalence of different bacterial species isolated from the 104-samples in Chennai, in the retrospective study is presented in table 1 . Table 2 presents the details of the most effective antimicrobial agents (AMAs) whose susceptibility patterns were in the range of $100.0 \%$ to $66.7 \%$ against the particular pathogen, namely, Pseudomonas aeruginosa (the bacterial resistances varying from $0.0 \%$ to $33.3 \%$ ).

According to the data shown in table 2, it becomes clear that any one of the five antimicrobial agents (AMAs) can be administered against Pseudomonas aeruginosa found in a diabetic foot ulcer patient, choosing either Imipenem or Pipeacillin or Amoxicillin/clavulanic acid, or Ceftazidime, or Gentamicin.

This result is presented in table 3, in comparison to the multicentre- trial studies carried out in the United States by Citron et al., (2007) who evaluated 7-antimicrobial agents to be effective against Pseudomonas aeruginosa, namely, Imipenem, Gentamicin, Ceftazidime, Piperacillin/ tazobactam, Amikacin, Ciprofloxacin, Levofloxacin, and Moxifloxacin. This implies that there is a closer agreement between our Chennai-data of the retrospective study, in comparison to the multicentre-study data of the United States.

Being encouraged by this trend, it was attempted to compare the antimicrobial sensitivity patterns of the other 8-pathogens, namely, Staphylococcus aureus (MSSA, MRSA), CONS spp, Streptococcus spp, Enterococcus spp, Corynebacterium spp, Escherichia coli, Klebsiella spp, and Proteus spp., choosing informations available in the published literature, as reported for 2-South Indian locations (Kelambakkam and Bengaluru), and 2-North Indian locations (Chandigarh and New Delhi), in contrast to similar data pertaining to the multicentre trial study in the United States, as shown in table 3. Several similarities are found among the antimicrobial agents evaluated in India and the United States, considering separately, the Gram-positive and Gram-negative aerobic bacterial categories. It is found that more number of antimicrobial agents are used in the antimicrobial susceptibility tests in India, than 
in the United States, perhaps due to the predominance of Gram-negative bacteria prevalent in diabetic foot ulcers in India or factors related to the commercial availability of the various classes of drugs, in different geographical locations of India.

In the case of the present study, it was assumed, hypothetically, that all the 9bacterial pathogens to be present in a single patient, namely, 5-Gram-positive pathogens (aerobic) and 4-Gram-negative pathogens (aerobic). A hypothetical estimate was made to identify the antimicrobial agents needed to be used against all the 9-pathogens, in order to obtain a cure for the patient.

Referring to table 3 , the antimicrobial agents evaluated in the 5-Indian cities, were compared, for optimally choosing the suitable antimicrobial agents, as detailed below:

Table.1 Isolation rate of other bacteria

(Number of isolates $=104)$

\begin{tabular}{|l|l|l|}
\hline S.no & Organism & No. of organisms (\%) \\
\hline A. & Gram-positive (aerobic): $(40.4 \%)$ & \\
1. & Staphylococcus aureus & $18(17.3 \%)$ \\
2. & Coagulase Negative Staphylococcus (CONS) & $11(10.6 \%)$ \\
3. & Streptococcus spp. & $6(5.8)$ \\
4. & Corynebacterium spp. & $4(3.8)$ \\
5. & Enterococcus spp. & $3(2.9$ \\
\hline B. & Gram-negative (aerobic): $(59.6 \%)$ & $23(22.2)$ \\
6. & Escherichia coli & $18(17.3)$ \\
7. & Pseudomonas aeruginosa & $11(10.6)$ \\
8. & Klebsiella spp. & $10(9.6)$ \\
9. & Proteus spp. &
\end{tabular}

Table.2 List of AMAs effective against Pseudomonas aeruginosa

(Total number of $\mathrm{P}$. aeruginosa isolates $=\mathrm{n}=18$ )

\begin{tabular}{|l|l|l|l|}
\hline S.no & Antimicrobial agent & No of resistant strains & \% Resistence \\
\hline 1. & Imipenem & 1 & 5.5 \\
\hline 2. & Piperacillin & 2 & 11.0 \\
\hline 3. & Co-amoxyclav & 4 & 22.0 \\
\hline 4. & Ceftazidime & 6 & 33.0 \\
\hline 5. & Gentamicin & 6 & 33.0 \\
\hline
\end{tabular}


Table.3 Comparison of antibiotic agents effective against pathogens found in diabetic foot ulcers, in the workable susceptibility range of $100.0 \%$ to $66.7 \%$

\begin{tabular}{|c|c|c|c|c|c|c|c|}
\hline $\begin{array}{l}\text { S. } \\
\text { No }\end{array}$ & $\begin{array}{l}\text { Micro- } \\
\text { Organism }\end{array}$ & \begin{tabular}{|l} 
(1) Multi-Centre \\
Trials (U.S.A).
\end{tabular} & $\begin{array}{l}\text { (2) Chennai } \\
\text { (S.India) }\end{array}$ & \begin{tabular}{|l|} 
(3) Kelam- \\
Bakkam,(S.India)
\end{tabular} & $\begin{array}{l}\text { (5) Bengaluru } \\
\text { (S.India) }\end{array}$ & $\begin{array}{l}\text { (7) Chandigarh } \\
\text { (N.India) }\end{array}$ & $\begin{array}{l}\text { (8) New Delhi } \\
\text { (N.India) }\end{array}$ \\
\hline 1. & P. aeruginosa & $\begin{array}{l}\text { Ak,G,Cip,I,Pi/t,Lev } \\
\text { Mxf,Caz }\end{array}$ & $\begin{array}{l}\text { Amc,Pi,G.I } \\
\text { Caz }\end{array}$ & $\begin{array}{l}\text { Ak,Crb,Ci,I } \\
\text { Mer,Pi/t,PmB,Cfs }\end{array}$ & $\begin{array}{l}\text { Ak,G,I,Pi/t,Lev } \\
\text { Mer,Tob }\end{array}$ & $\begin{array}{l}\text { Ak,Pi,Tob,I } \\
\text { Ctr,Caz,Cfs }\end{array}$ & $\begin{array}{l}\text { Ak,I,Mer,Pi/t } \\
\text { Tcc,Cfs }\end{array}$ \\
\hline 2. & S, aureus & & & & \begin{tabular}{|l} 
Cldm,Ofl,Oxa,E,G \\
Lom,Tet,Lin,Van Cpz
\end{tabular} & $\begin{array}{l}\text { Amp,Amc,Cip G, } \\
\text { E,I,Ctr, Cfrxm,Cfs }\end{array}$ & Rif \\
\hline 2.11 & MSSA & $\begin{array}{l}\text { Amc,Etp,Pi/t,Lev } \\
\text { Mxf,Cip,Cldm } \\
\text { T/S,Dox, Cfl }\end{array}$ & .......... & \begin{tabular}{|l|} 
G,Ntlmc,E,Cldm, \\
Clrmp,Van,Lin,Rif \\
Teic,Clxcln,Cfzln Cot
\end{tabular} & $\ldots$ & $\ldots$ & $\ldots \ldots$ \\
\hline 2.2 .2 & MRSA & \begin{tabular}{|l|} 
Dox \\
$\mathrm{T} / \mathrm{S}$ \\
\end{tabular} & ...... & $\begin{array}{l}\text { Ntlmc,Cldm,Van } \\
\text { Clrmp,Teic,Lin }\end{array}$ & $\ldots \ldots$ & $\ldots$ & $\ldots$. \\
\hline 3. & $\begin{array}{l}\text { CONS } \\
\text { Spp. }\end{array}$ & $\begin{array}{l}\text { Amc,Etp,Pi/t,LevMxf, } \\
\text { Cldm,T/S,Cip,Dox,Cfl }\end{array}$ & $\ldots$ & $\begin{array}{l}\text { Ntlmc,Lin } \\
\text { Van, Teic }\end{array}$ & $\begin{array}{l}\text { Amc,Cldm,Ofl.Oxa } \\
\text { G,Tet,Lin,Van,Cpz,Cpm }\end{array}$ & $\ldots$ & $\begin{array}{l}\text { Ak, Tet,Cldm } \\
\text { Clrmp,Rif,Cot }\end{array}$ \\
\hline 4. & Streptococcus spp. & $\begin{array}{l}\text { Amc,Etp,Lev,Mxf } \\
\text { Cip,Cldm,Pi/t } \\
\text { T/S,Cfl }\end{array}$ & $\ldots$ & $\begin{array}{l}\text { Ofl,Van,Teic } \\
\text { Tet,Cldm,,Lin }\end{array}$ & $\begin{array}{l}\text { (S.pyo):Amc,Cdm,E } \\
\text { Ofl,Oxa,Lom,G,Lin } \\
\text { Tet,Van,Cpz,Cpm }\end{array}$ & $\ldots$ & $\ldots$ \\
\hline 5. & $\begin{array}{l}\text { Enterococcus } \\
\text { Spp. }\end{array}$ & $\begin{array}{l}\text { Amc,Pi/t,Cip,Lev } \\
\text { Mxf,T/S }\end{array}$ & $\ldots$ & & Amc,Tet,Lin,Van & $\begin{array}{l}\text { (E.faec)Amc, } \\
\text { Caz,Cfs, G }\end{array}$ & $\ldots$ \\
\hline 7.1 & $\begin{array}{l}\text { Corynebacterium } \\
\text { Spp. } \\
\text { Entero- } \\
\text { Bacteriaceae }\end{array}$ & $\begin{array}{l}\text { Amc,Etp,Pi/t } \\
\text { Dox, Cfl } \\
\text { Ak, Etp,I,Pi/t,G,Cip } \\
\text { Lev,Mxf,Dox,T/S, } \\
\text { Caz }\end{array}$ & & $\begin{array}{l}\cdots \\
\text { Ak,Tet,Tob,G,Cip } \\
\text { Mer,Ofl,Ci,Pi/t } \\
\text { Clrmp,I,PmB,Cot } \\
\text { Cpm, Cfs,Cfrxm } \\
\text { Cftxm }\end{array}$ & $\begin{array}{l}\text { Ak, Cip,G,Lev,Pi/t } \\
\text { Mer,Tob,Ntlmc }\end{array}$ & $\ldots$ & $\ldots$ \\
\hline 7.21 & E. coli & & $\cdots \cdots$ & $\begin{array}{l}\mathrm{Ak}, \mathrm{I}, \mathrm{G} \text { Pi/t,Clrmp } \\
\mathrm{Ci}, \mathrm{PmB}, \mathrm{Cfs}\end{array}$ & $\begin{array}{l}\text { Ak, G,I, } \\
\text { Lev,Pi/t }\end{array}$ & \begin{tabular}{|l} 
Ak,I,Cfs \\
Caz
\end{tabular} & $\begin{array}{l}\text { I, Mer,Tcc } \\
\text { Cfs }\end{array}$ \\
\hline 8. & \begin{tabular}{|l} 
Klebsiella \\
Spp.
\end{tabular} & $\ldots \ldots$ & $\ldots$ & $\begin{array}{l}\text { Ak, I,Mer,Pi/t, Ci } \\
\text { PmB,Cfs }\end{array}$ & Ak,G,I,Lev,Pi/t & $\begin{array}{l}\text { (K.oxy)Ak,I,Cfs, } \\
\text { Caz (K.pne) } \\
\text { I,Ctr,Cfs }\end{array}$ & $\begin{array}{l}\text { (K.pne) Amc,Cip } \\
\text { Mer,Pi/t,Tcc,Cfs } \\
\text { Ak,I,Caz,Cftxm }\end{array}$ \\
\hline 9. & $\begin{array}{l}\text { Proteus } \\
\text { Spp. }\end{array}$ & $\begin{array}{l}\text { Etp,I, Pi/t,Ak,Cip,Lev } \\
\text { Mxf,G,T/S,Dox,Caz }\end{array}$ & $\ldots \ldots$ & $\begin{array}{l}\text { Cfs, I,Clrmp } \\
\text { Tet, Pi/t }\end{array}$ & $\begin{array}{l}\text { Ak, I,G.Cip,Lev,Pi/t } \\
\text { Cfrxm,Cpm,Cpz }\end{array}$ & $\begin{array}{l}\text { (P.vul)Ak,G,I, } \\
\text { Caz,Cfs,Cfrxm Ctr }\end{array}$ & \begin{tabular}{|l|} 
I,Cip,Tcc \\
Mer,Cfs
\end{tabular} \\
\hline
\end{tabular}

Amp=Ampicillin;Amc=Amoxicillin/clavulaninicacid;Ak=Amikacin; Caz=Ceftazidime;Ctr=Ceftriaxone;Cip=Ciprofloxacin;Cftxm=Cefotaxime; Cfrxm=Cefuroxime; $\mathrm{Cfl}=$ Cefalexin; Cfzln=Cefazolin; $\mathrm{Cpm}=$ Cefepime; $\mathrm{Cpz}=\mathrm{Cefoperazone} ; \mathrm{Cfs}=\mathrm{Cefoperazone} / \mathrm{sulbactam}$; $\mathrm{Crb}=\mathrm{Carbenicillin}$;

Cot=Cotrimoxazole; Cldm=Clindamycin; $\mathrm{Ci}=$ Colistin; Clxcln=Cloxacillin; Clrmp=Chloramphenicol; Dox=Doxycycline; E=Erythromycin; Etp=Ertapenem; G=Gentamicin; I=Imipenem; Lev=Levofloxacin; Lin=Linezolid; Lom=Lomefloxacin; Mer=Meropenem; Mxf=Moxifloxcin; Ntlmc=Netimycin; Oxa=Oxacillin; Ofl=Ofloxacin; Pi=Piperacillin; Pi/t=Piperacillin/tazobactam; PmB=PolymixinB; Rif=Rifampicin; Tcc=Ticarcillin/clavulanicacid; Tet=Tetracycline;

Teic=Teicoplanin; Tob=Tobramycin; T/S=Trimethoprim/sulfamethoxazole; Van=Vancomycin 
Case-1: For the 4-species of Gram-positive bacteria present in the diabetic ulcer wound, namely, Staphylococcus aureus, Coagulase negative staphylococcus (CONS) species, Streptococcus species, and Enterococcus species, the recommended AMAs, would be Linezolid or Vancomycin, as evaluated in India. For the Corynebacterium species, Amoxicillin/clavulanate may be tried as reported in the multi centre-trial data of the United States, in the absence of Indian data for this particular pathogen.

Case-2: For the 4-numbers of Gram-negative bacterial species present in the same diabetic foot ulcer wound, namely, Escherichia coli, Klebsiella species, Proteus species and Pseudomonas aeruginosa, the recommended AMAs would be either Piperacillin/ tazobactam, or Cefoperazone/ sulbactam, or Imipenem (chosen from data reported for the 5-Indian cities).

In addition to the estimates made in Case-1 and Case-2, it is to be said that appropriate medication must be included for covering the anaerobic pathogens and fungal pathogens, if present in any other situation.

Metronidazole has been reported to be effective against majority of anaerobic pathogens (Anandi et al., 2004; Chincholikar, 2002). An antifungal cream (such as Fluconazole) must be included in the list, as a topical medicine, if fungal pathogens are present (Sanniyasi et al., 2015). Also, Citron et al., (2007) reported that Ertapenem, Piperacillin / tazobactam, Amoxicillin / clavulanic acid, or Clindamycin could be effective against the anaerobic pathogens found in diabetic foot infections.

Thus, all these medicines administered on a hypothetical patient would represent the "drug-burden", on the patient, in addition to the anti-diabetes (oral-hypoglycemic) drugs to be consumed by the patient, for the purpose of maintaining a normal glycemic control.

There is, therefore, a necessity to optimize on the number of drugs to be administered on the patient, by choosing the AMAs, in such a way that the chosen drug would be effective against more than one pathogen, without causing any adverse effect.

The choice of drugs to be administered is to be left to the prerogative decision of the team of experts who attend on the diabetic foot ulcer patient. The input from a microbiologist is needed during the various stages of the treatment process.

Certain antimicrobial agents such as Ertapenem, Tigecycline, Doxycycline, Trimethoprim/ sulfamethoxazole, etc., found useful in the multicentre studies in the United States, can be included in the in-vitro susceptibility tests in India, to assess their effectiveness in offering treatment to diabetic foot infections.

\section{Acknowledgement}

The authors are grateful to the wisdom of all other investigators whose findings have been cited.

\section{References}

Anandi, C., Alaguraja, D., Natarajan, V., Ramanathan, M., Subramaniam, C.S., Thulasiram, M., Sumithra, S., 2004, "Bacteriology of foot infections". Indian J. Med. Microbiol., 22: 175- 178.

Anderson, L. 2017. "Antibiotics-Common Side Effects, Allergies and Reactions", Drugs.com, Know More, Be sure, (Medically reviewed on March 5, 2017.

Armstrong, D.G., and Lipsky, B.A. 2004. "Diabetic foot infections: stepwise medical and surgical management", Int. 
Wound J., 1(2):123-32. (doi:10.1111/j. 1742-4801.2004.00035.x).

Bansal, E., Garg, A., Bhatia, A., Attri, A.K., Chander, J., 2008. "Spectrum of Microbial Flora in Diabetic Foot Ulcers", Indian J. Pathol. Microbiol., 51: 204-208.

Borish, L., Tamir, R., Rossenwaser, L.J., 1987. "Intravenous desensitisation to betalactam antibiotics", The J. Allergy and Clin. Immunol., 80(3): 314-319.

Bronze, M.S., Khardori, R. 2016. "Diabetic Foot Infections Medication: Penicillin, Cephalosporins", emedicine. medscape.com/article/237378-medication \#2. (Updated April 05, 2017).

Cavanagh, P.R., Lipsky, B.A., Bradbury, A.W., Botek, G. 2005. "Treatment for Diabetic Foot Ulcers". Lancet, 366(9498): 1725175.

Chincholikar, D.A., Pal, R.B. 2002. A study of fungal and bacteriological infections of the diabetic foot. Indian J. Pathol. Microbiol., 45:15-22.

Citron, D.M., Goldstein, E.J.C., Merriam, C.V., Lipsky, B.A., Abraham, M.A. 2007. "Bacteriology of the moderate to severe diabetic foot infections and the in-vitro activity of the antimicrobial agents", $J$. Clin. Micobiol., 45(9): 2819-28.

Clinicaltrials.gov: Trial record 13 of 82 for: drugs for diabetic foot infections: "Study Evaluating the Safety and Efficacy of a Once-daily Dose of Tigecycline versus Ertapenem in Diabetic Foot Infections (DFI) with a Sub-study in Patients with Diabetic Foot Infections complicated by Osteomyelitis". (Clinical Trials. gov. identifier: NCT00366249 Last updated April 2010).

Edmonds, M. 2009. "The treatment of diabetic foot infection: Focus on Ertapenem", Vasc. Health Risk Manag., 5: 949-963.

Fernando, M.E., Seneviratne, R.M., Tan, Y., Lazzarini, P.A., Sangla, K.S., Cunningham, M., Buttner, P.G., Golledge, J. 2016. "Intensive versus conventional glycemic control for treating diabetic foot ulcers", Cochrane Database of Systematic Rev., doi: 10.1002/14651858.CDO10764.pub2.

Gadapalli, R., Dhawan, B., Sreenivas, V. et al. 2006. "A Clinico-microbiological studyof diabetic Foot Ulcers in an Indian Tertiary Care Hospital", Diabetes Care, 29: 17271732.

Grayson, M.L. 1995. "Diabetic foot infections: Antibiotic therapy", Infect. Dis. Clin. North Am., 9:143-61.

Green, C.R., Rosenblum, A. 1971, “A report of the penicillin study group", J. Allergy Clin. Immunol., 48: 331.

Heine, H. 1997. "Cutaneous adverse reaction to ciprofloxacin: demonstration of specific lymphocyte Proliferation and crossreactivity to ofloxacin in vitro", Acta Dermato-Venereol., 77: 285-286.

Ho Kwong Li, Mathew Searborough, et al. 2015. "Oral versus intravenous antibiotic treatment for bone and joint intervention (OVIV): study protocol for a randomized controlled trial", Trials, 16: 583. PMCID: PMC4687165.

Joseph, W.S., and Axler, D.A. 1990. Microbiology and antimicrobial therapy for diabetic foot infections, Clin. Podiatr. Med. Surg., 7(3): 467-81.

Kendall, C., and Wooltorton, E. 2006. People with diabetes should avoid antibiotic Gatifloxacin, Canadian Med. Association J., 174(8): 1089-1090. PMCID: 1421471.

Kruse, I., and Edelman, S. 2006. "Evaluation and Treatment of Diabetic Foot Ulcers", American Diabetes Association: Clin. Diabetes, 24(2): 91-93. (https://doi.org/10.2337/diaclin.24.2.91)

Lauf, L., Ozsvar, Z., Mitha, I., Regoli-Merei, J., Embil, J.M., Coope, A., Sabol, M.B., Castaing, N., Dartois, N., Yan, J., Dukart, G., Maroka, R. 2014. "Phase 3 study of comparing Tygecycline and Ertapenem in patients with diabetic foot infection with and without Osteomyelitis", Diagn. Microbiol. Infect. Dis., 78(4): 469-80. (doi: 10/1016/j.diagmicrobio.2013.12. 007). 
Lipsky, B.A., 2009 Diagnosing and Treating Diabetic Foot Infections, Klimik Dergisi; 22(1): 2-13.

Lauf, L., Ozsvar, Z., Mitha, I., Regoli-Merei, J., Embil, J.M., Coope, A., Sabol, M.B., Castaing, N., Dartois, N., Maroko, R. 2014. Phase 3 study of comparing Tygecycline and Ertapenem in patients with diabetic foot infection with and without Osteomyelitis, Diagn. Microbial. Infect. Dis., 78(4): 469-80.

Lipsky, B.A., Armstrong, D.G., Citron, D.M., Tice, A.D., Morgenstern, D.E., Abramson, M.A. 2005. Ertapenem versus Piperacillin/tazobactam for diabetic (SIDESTEP): prospective, randomized, controlled, double-blinded, multicenter trial. Lancet, 366(9498): 1695-1703.

Lipsky, B.A. 2007. Empirical therapy for diabetic foot infections: Are there clinical clues to guide antibiotic selection? Clin. Microbiol. Infect., 13(4): 3513.PMID:17359317. (doi:10.1111/j.14690691.2007.01697.x).

Lipsky, B.A., Berendt, A.R., Cornia, P.B., Plie, J.C., Peters, E.J.G., Armstrong, D.G., Deery, H.G., Embil, J.M., Joseph, W.S., Karchmer, A.W., Pinzur, M.S., and Senneville, E. 2012. 2012 Infectious Disease Society of America Clinical Practice Guidelines for the Diagnosis and Treatment of Diabetic Foot Infections, Clin. Infect. Dis., 54(12): 132-137.

Lipsky, B.A., Peters, E.J.C., Sonneville, E., Berendt, A.R., Embil, J.M., Lavery, L.A., Urbancic-Rovan, V., Jeffcoate, W.J. 2012(b). "Expert Opinion on the Management of Infections in the Diabetic foot", Diabetes Metabolism Res. Rev., 38( S1): 163-178. doi:10.1002/dmrr.2248,

Lipsky, B.A., Berendt, A.R., Deery, H.G., Emil, J.M., Joseph, W.S., Karchmer, A.W., LeFock, J.L., Lew, D.P., Mader, J.T., Norden, C., and Tan, J.S. 2004. "Diagnosis and Treatment of Diabetic Foot Infections", Clin. Infect. Dis., 39(7): 885-910. doi:10.1086/424846.

Lipsky, B.A., Holoyd, K.J., Zasloff, M. 2008. "Topical versus systemic antimicrobial therapy for treating mildly infected diabetic foot ulcers:a randomized, controlled, double-blinded multi-centre trial of Pexiganan Cream", Clin. Infect. Dis., 47: 1537-45.

Manfredi, M., Severino, M., Testi, S., et al. 2004. "Detection of specific IgE to quinolones", J. Allergy Clin. Immunol., 113: $155-160$.

Mayo Clinic: Diseases and Conditions: Diabetic hypoglycaemia. 2015.

Meenakshisundaram, C., UshaAnandRao, Rajendran, P., Mohan, V., and Vasudevan, R. 2015. "Characerisation of Pseudomonas aeruginosa and its association with Diabetic Foot ulcer isolated from a tertiary care hospital in Tamilnadu, India", Int. J. Curr. Microb. and App. Sci., Vol.4: No.7: pp.122-126.

Meenakshisundaram, C., Uma Rani, J., Usha Anand Rao, Mohan, V., and Vasudevan, R. 2016. "Microbial Profiles of Diabetic Foot Ulcers: A random Comparison within India", Int. J. Curr. Microbiol. and App. Sci., 5(12): 835-849. (http://dx.doi.org/10.20546/ijcmas.2016.5 12.092).

National Committee for Clinical Laboratory Standard: Performance Standard for Antimicrobial Susceptibility Testing: Twelfth information standard: M100-S 12, Vol.22,no.1, Villanova, Pa, National Committee for Clinical Laboratory Standard, 2002.

National Treatment Guidelines for Antimicrobials Use in Infectious Diseases (version 1.0 (2016), National Centre for Disease Control, Director General of Health Services, Ministry of Health \& Family Welfare, Government of India, New Delhi.

Parker, C.W. 1972. "Allergic drug responses mechanisms and unsolved problems", CRC Crit. Rev. Toxicol., 1: 261.

Priyadarshini, S., Jeya, M., Linda Susan, S., 2013, "The Bacteriology of Diabetic Foot Ulcers, with a Special Reference to Multidrug Resistant Strains", J. Clin. Diagn. Res., 7(3): 441-445. (Pub Med). 
Pumphrey, R.S.H., Dais, S. 1999. "Underreporting of antibiotic anaphylaxis may put patients at risk", Lancet, 353: 11571158.

Rao, N., and Lipsky, B.A. 2007. "Optimising antimicrobial therapy in diabetic foot infections", Drugs, 67(2): 195-214. PMID: 17284084.

Reiber, G., Lipsky, B.A., Gibbons G.W. 1998. "The burden of diabetic foot ulcers", The American J. Surgery, 176(2): Suppl 1:5S10S. doi:10.1016/S0002-9610(98)001810 .

Richard, J.L., Sotto, A., Jourdon, N., et al. 2008. "Risk factors and healing impact of multi-drug resistant bacteria in diabetic foot ulcers", Diabetes Metab., 34: 363369.

Romano, A., Gueant-Rodiguez, R.M., Viola, M., et al. 2004. "Cross-reactivity and tolerability of cephalosporins in patients with hypersensitivity to penicillins", Ann. Intern. Med., 141: 16-22.

Romano, A., Viola, M., Gueant-Rodriguez, R.M., et al. 2006. "Imipenem in patients with immediate hypersensitivity to penicillins", N. Eng. J. Med., 354: 28352837.

Romano, A., Viola, M., Gueant-Rodriguez, R.M., et al. 2007. "Tolerability of meropenem in patients with IgE-mediated Hypersensitivity to penicillins", Ann. Intern. Med., 146: 266-269.

Rowe, V.L., and Khardori, R., et al., (updated March 14), 2017. Diabetic Ulcer Treatment and Management, MedScape, Drugs and Diseases. (emedicine.medscape.com/article/460282 -treatment).

Sachs, B., Reigel, S., Seebeck, J., et al., 2006. "Fluoroquinolone-associated anaphylaxis in spontaneous Adverse drug reaction reports in Germany: differences in reporting rates between individual Fluoroquinolones and occurrence after first-ever use", Drug Saf., 29: 1087-1100.

Sajila, N.M., Manjunath, R., Mahesh Desai. May 2015. "A study of the bacteriology profile of Diabetic Foot Ulcer, and
Antibiotic Sensitivity Pattern", J. Evol. Med. Dent. Sci., 4(35): 6832-6840. doi:10.14260/jemds/2015/991.

Salpeter, S., Greyber, E., Pastenack, G., Salpeter, E. 2006. "Risk of fatal and nonfatal lactic acidosis with Metformin use in type2 Mellitus", Ochrane Database Rev., 2006. CD 002967.

Sanniyasi, S., Balu, J., Narayanan, C.D. 2015. "Fungal Infection: A hidden enemy in Diabetic Foot Ulcers", The J. Foot and Ankle Surgery (Asia Pacific), July-Dec., Sri Ramachandra University, Chennai, 2(2): 74-76. doi: 10.5005/jp-journals10040-1033.

Sawin, G., Shaunghnessy, A.F. 2010. "Glucose control in hospitalized patients", Am. Fam. Physician, 81: 1121-4.

Shahi, S.K., Kumar, A., Gupta, S.K., and Singh, S.K. 4 Dec., 2013. "Occurrence of Multiple antibiotic resistance phenotype and class 1-integron in bacteria isolated from diabetic foot ulcers", African $J$. Microbiol. Res., 7(48): 5424-5432. doi:10.5897/AJMR12.979.

Smith Marsch, D.E. 2017. "Severity of Adverse Drug Reactions: Some serious Adverse Drug Effects", in MDS Manual: Professional/Clinical pharmacology/ Adverse reactions.

Solensky, R., and Khan, D.A. 2010. "Drug Allergy: An Updated Practice Parameter", Annals of Allergy, Asthma and Immunol., (www.jcaai.org) Pp. 273.e9.

Stevens, D.L., Bisno, A.L., Chambers, H.F., Everett, E.D., Dellinger, P., Goldstein, E.J.C., Gorbach, S.L, Hirscmann, J.V., Kaplan, E.L., Montoya, J.G., and Wade, J.C. 2005. "Practice Guidelines for the diagnosis and Management of Skin and Soft Tissue Infections", Clin. Infect. Dis., 41(10):1373-1406. doi:10.1086/497143.

Thomas Higgins. 2017. Boulder Medical Centre.

Uckay, I., Pittet, D., Vasudaux, P., Sax, H., Lew, D., Walvogel, F. 2009. "Foreign body infections due to Staphylococcus epidermidis", Ann. Med., 41:109-119. 
Venturini Diaz, M., Lobera Labairu, T., delPozo Gil, et al. 2007. "In-vivo diagnostic tests in adverse reactions to Quinolones", $J$. Investig. Allergol. Clin. Immunol., 17: 393-398.

Weng, Q.Y., Raff, A.B., Cohen, J.M., et al. 2017. "Costs and Consequences Associated with Misdiagnosed Cellulitis", JAMA. Dermatol., 153(2): 141-146. doi: 10.1001/jamadermatol.2016.3816.
Xu, Z.R, Ran, X.W., Xian, Y., Yan, X.D., Yuan, G.Y., Mu, S.M., Shen, J.F., Zhang, B.S., Gan, W.J., Wang, J. 2016. "Ertapenem versus piperacillin/tazobactam for diabetic foot infections in China: a Phase 3, muliticentre, randomized, double blind, active-controlled, non-inferiority trial", $J$. Antimicrob. Chemother., 71(6): 16881696.

\section{How to cite this article:}

Meenakshisundaram, C., J. Uma Rani, Usha Anand Rao, V. Mohan and Vasudevan, R. 2017. Hypothetical Estimate of Drug-Burden on a Diabetic Foot Ulcer Patient, and Its Relevance to Microbiological Analysis. Int.J.Curr.Microbiol.App.Sci. 6(6): 1139-1153. doi: https://doi.org/10.20546/ijcmas.2017.606.132 